\title{
Nondestructive investigation on the 17-18th centuries Sicilian jewelry collection at the Messina regional museum using mobile Raman equipment
}

\author{
G. Barone, ${ }^{a *}$ D. Bersani, ${ }^{b}$ J. Jehlička, ${ }^{c}$ P. P. Lottici, ${ }^{b}$ P. Mazzoleni, ${ }^{a}$ S. Raneri, ${ }^{a}$ \\ P. Vandenabeele, ${ }^{d}$ C. Di Giacomo ${ }^{\mathrm{e}}$ and G. Larinà ${ }^{\mathrm{e}}$
}

In recent years, the use of mobile Raman equipment as an archeological, artistic, and conservation tool has largely increased due to the possibility to obtain quick and nondestructive compositional analysis on precious, vulnerable, and unique art objects. In particular, art and archeological museums can take great advantage in carrying out in situ measurements in short times and without moving the artifacts. In this work, we report on the Raman measurements carried out by portable instruments on an important jewelry collection dated back to 17th-18th centuries and preserved in the Messina Regional Museum (Sicily, Italy) with the goal to verify the identification of the gems and gemological materials of the collection, previously made by conservators. Although most of the previous identifications were confirmed, some important reclassifications have been proposed. Finally, interesting and unusual combinations of different materials were detected in some jewels. Copyright $\odot 2015$ John Wiley \& Sons, Ltd.

Additional supporting information may be found in the online version of this article at the publisher's web site.

Keywords: gems; jewelry; jewels; portable Raman spectrometer; handheld Raman spectrometer

\section{Introduction}

The Messina Interdisciplinary Regional Museum Maria Accascina (Messina, Sicily, Italy) preserves a wide typology of artifacts coming from the old town Museum or collected after the well-known earthquake that destroyed it in 1908, Messina and Reggio Calabria. Among the numerous art objects, the Sicilian jewels represent one of the most relevant collections preserved in the Museum. The collection essentially consists of precious and unique ex voto jewels made by Messinian goldsmiths during the 17-18th centuries mainly coming from Monasteries and Churches of the town. On the whole, they exhibit a high manufacture level and decorative motif obtained by using both precious gemstones and glazes, resembling the more famous Trapani and Palermo jewelry production. Unfortunately, during the centuries, they suffer forgeries, attested since 1950s, probably occurred during the transfer from one Museum to another. For this reason, scientific investigations are required in order to verify the possible replacement of rare gems with other more common and less valuable imitations. Considering the high artistic value of the studied objects, only non-destructive and non-invasive analyses can be performed. Further, portable instruments are necessary for the study of museum materials or of gems mounted in precious and unmovable artworks that, as in our case, cannot be brought in the laboratory.

Raman spectroscopy has been proved to be a powerful tool for analysis of gems and gemstones (Bersani and Lottici ${ }^{[1]}$, Kiefert and Karampelas ${ }^{[2]}$, Dele-Dubois et al. ${ }^{[3]}$, and references therein). Recently, several projects have been carried out to highlight the potentiality of portable and micro-Raman apparatus in identifying minerals in various contexts. Excellent discrimination of sulfates, oxides, and silicates was obtained using a portable Raman system with $785-n m$ excitation. ${ }^{[4,5]}$ Similarly, very good results were obtained in the identification of macroscopically very similar white to yellowish zeolites ${ }^{[6]}$ and carbonates. ${ }^{[7]}$ In the Cultural Heritage field, several Raman microspectroscopic studies were performed on historical artifacts of value. ${ }^{[8,9]}$ Reiche et al. 2004 ${ }^{[10]}$ applied the in situ Raman analysis on the reliquary Heinrich's Cross part of the treasury of the Basel Cathedral while Karampelas et al. (2010) successfully studied the gems of a ciborium in the Einsiedeln Abbey. ${ }^{[11]}$

The major tasks for Raman spectroscopy in gemology are the following: (i) identification of the minerals; (ii) rough estimation

* Correspondence to: Germana Barone, Department of Biological, Geological and Environmental Sciences, University of Catania, C.so Italia, 5795129 Catania, Italy.E-mail: gbarone@unict.it

a Department of Biological, Geological and Environmental Sciences, University of Catania, C.so Italia, 5795129 Catania, Italy

b Department of Physics and Earth Sciences, University of Parma, Parco Area delle Scienze, 7/A 43124 Parma, Italy

c Institute of Geochemistry, Mineralogy and Mineral Resources, Charles University in Prague, Faculty of Science, Albertov 6, 12843 Prague, Czech Republic

d Department of Archaeology, Ghent University, Sint-Pietersnieuwstraat 35, 9000 Gent, Belgium

e Viale della Libertà, Messina Regional Museum, 465, 98121 Messina, Italy 
of the chemical composition (i.e. in the case of garnets); (iii) detection of enhancement treatments; and (iv) detection of potential inclusions. The last issue can be of major relevance for discriminating synthetic and natural gemstones as well as for provenance studies. However, these goals can generally be reached under laboratory conditions, with powerful dispersive Raman microspectrometers.

Regarding the aim of the work, up to now, there are only few cases of the use of portable or even handheld instruments. Mainly, $\mathrm{SiO}_{2}$ forms (moss agate, carnelian, amethyst, citrine, and also the dyed bluish green chalcedony) and garnets were detected using a 785-nm equipped system in the silver scepter of the Charles University (Prague) from the mid-1920s. ${ }^{[12]}$ Osterrohová et al. ${ }^{[13]}$ investigated gemstones (gems, glass, and corals) mounted in a silver Torah shield crafted in Poland (first half of the 19th century) using two of the currently supplied portable/handheld Raman spectrometers. A Raman spectrometer equipped with a 785-nm diode offered good performance, high speed and accuracy for the identification of all of the gemstones and glass imitations. In the case of the red corals, it was beneficial to use for the unambiguous identification of their natural pigments resonance Raman conditions (a handheld Raman spectrometer with 532-nm laser excitation). Finally, recent researches on natural gems and simulant of sapphire, ${ }^{[14]}$ emeralds ${ }^{[15]}$ and rubies highlighted the importance of the complementary use of portable and micro-Raman analysis for provenance and genesis study.

For the aforementioned studes, with the aim at confirming the archeological hypotheses and evaluating the artifacts by nondestructive and in situ scientific investigations, some important Museums and the Universities of Catania, Parma, Prague and Ghent have launched an interdisciplinary project to evaluate such artifacts.

\section{Experimental}

\section{Materials}

Fifteen jewels, namely necklaces, earrings, rings, brooches, hair clips and precious belts were selected among the valuable and precious jewelry collection. In Table 1, sample IDs, historical and descriptive information $^{[16,17]}$ of the studied jewels are summarized.

All the jewels can be ascribed to the Sicilian manufacturing. In detail, the jewels A96a and A96b are part of a unique assembled necklace composed of a gold half-moon chocker in which are set pearls and topazes and a bad conserved Liberty style gold necklace embellished by orange agate. The medallion labeled as A104 is a devotional object composed by a gold frame decorated with rubies and diamonds and a hand-painted Nativity scene. From a stylistic point of view, the artifact is attributed to the XVII or XVIII century. Referring to the earrings $A 105$, they are composed of two elements, decorated with pearls and red glass. The features of the earring latch allow dating the jewel between 1839 and 1873. The gold cross pendant with rubies A106 is inspired to XVII century French manufacture. However, stylistic features and the presence of Messinian trademark allow dating the object to the XVIII century. About the flowering branch A107, it may be part of a vessel usually located on a religious altar. The use of glazes and the decorative motif is typical of Baroque jewelry made in Messina during the end of XVII century. The hair clip A108 is made by golden copper, silver, pearls, emeralds, rubies, and diamonds. It exhibits Baroque stylist elements. The earrings $A 113$ are made by gold and silver, with diamonds and pearls, and exhibit a Légaré bow inspired to the XVII century French production; however, the jewel can be ascribed to the XVIII century. The cross, labeled as A115, composed of silver, emeralds and diamonds may be dated back to XVIII century. The

\begin{tabular}{|c|c|c|c|c|}
\hline Sample ID & Jewel & Dimension & Archeological information & Date \\
\hline A96a & Half-moon shape choker & $11 \times 2 \mathrm{~cm}$ & $\begin{array}{l}\text { Messinian goldsmith, provenance Minoriti Church, } \\
\text { Messina }\end{array}$ & End of XVII-XIX centuries \\
\hline A96b & Necklace & $3.5 \times 28 \mathrm{~cm}$ & $\begin{array}{l}\text { Messinian goldsmith, provenance Minoriti Church, } \\
\text { Messina }\end{array}$ & End of XVII-XIX centuries \\
\hline A104 & $\begin{array}{l}\text { Medallion with Nativity } \\
\text { scene and HIS inscription }\end{array}$ & $4 \times 4 \mathrm{~cm}$ & $\begin{array}{l}\text { Messinian goldsmith, provenance San Francesco } \\
\text { all'Immacolata Church, Messina }\end{array}$ & XVIII century \\
\hline A105 & Earrings & $5 \times 2 \mathrm{~cm}$ & Messinian goldsmith & $1839-1873$ \\
\hline A106 & Cross shaped pendant & $5 \times 5 \mathrm{~cm}$ & $\begin{array}{l}\text { Messinian goldsmith, provenance Benedittine } \\
\text { cloister, Mirto (Messina) }\end{array}$ & XVIII century \\
\hline A107 & Flowering branch & $18 \times 8.5 \mathrm{~cm}$ & Messinian goldsmith & End of XVII century \\
\hline A108 & Hair clip & $4.7 \times 5 \mathrm{~cm}$ & Messinian goldsmith & XVIII century \\
\hline A113 & Earrings & $7.5 \times 4.5 \mathrm{~cm}$ & $\begin{array}{l}\text { Messinian goldsmith, provenance San Francesco } \\
\text { all'Immacolata Church, Messina }\end{array}$ & XVIII century \\
\hline A115 & Cross & $6.5 \times 5 \mathrm{~cm}$ & $\begin{array}{l}\text { Messinian goldsmith, provenance S. Gioacchino } \\
\text { Church, Messina }\end{array}$ & XVIII century \\
\hline A119 & Earrings & $3 \times 2.5 \mathrm{~cm}$ & Messinian goldsmith & $1839-1873$ \\
\hline A121 & Earrings & $4.4 \times 3 \mathrm{~cm}$ & Messinian goldsmith & XVIII century \\
\hline A123 & Earrings & $6.5 \times 2 \mathrm{~cm}$ & $\begin{array}{l}\text { Messinian goldsmith, provenance San Francesco } \\
\text { all'Immacolata Church, Messina }\end{array}$ & XIX century \\
\hline A125 & Ring & $2 \times 2 \mathrm{~cm}$ & $\begin{array}{l}\text { Messinian goldsmith, provenance San Francesco } \\
\text { all'Immacolata Church, Messina }\end{array}$ & XVIII century \\
\hline A128 & Ring & $2 \times 2 \mathrm{~cm}$ & $\begin{array}{l}\text { Messinian goldsmith, provenance San Francesco } \\
\text { all'Immacolata Church, Messina }\end{array}$ & XVIII century \\
\hline A160 & Belt & $12 \times 9.6 \mathrm{~cm}$ & $\begin{array}{l}\text { Messinian goldsmith, provenance Citizen Museum } \\
\text { San Gregorio, Messina }\end{array}$ & XVIII century \\
\hline
\end{tabular}


silver earrings A119 decorated with rubies and diamonds is datable between 1839 and 1873. Referring to the pinwheel earring $A 121$, it is made by gold and rubies. It exhibits decorative motif and stylistic French XVII century jewelry features; however, the trademark allows dating the object to the XVIII century. The diamond earrings A123 are an ex voto and exhibit a jewelry style typical of the XIX century. Also the rings $A 125$ and $A 128$ are ex voto. The first one is made by gold and silver with rubies and diamonds. The setting of the gemstone and the stylistic features allow dating the jewel at about the second half of the XVIII century. The latter one, maybe an engagement ring with gold, rubies, emeralds, and diamonds, exhibits a Baroque style. Finally, the fashionable gold belt A160 decorated with glass mirrors represents a very rare jewel in the local scenario. The artifact exhibits stylistic features and setting of the gemstones typical of the XVIII century.

\section{Methods}

The portable Rock Hound (DeltaNu) Raman instrument weights $1.9 \mathrm{~kg}$ and is equipped with a $785 \mathrm{~nm}$ diode laser at maximum output power of $120 \mathrm{~mW}$ and a thermoelectrically cooled CCD detector. It gives Raman spectra over the wavenumber range 200$2000 \mathrm{~cm}^{-1}$ with a spectral resolution of $8 \mathrm{~cm}^{-1}$. This instrument is controlled remotely via a USB cable connected laptop. It allows the operator to select from a wider range of settings for measurements including more detailed power output selection, number of accumulations, and long accumulation times. The spectra were typically recorded in situ collecting one accumulation each of $2 \mathrm{~s} d u-$ ration. The instrument was calibrated by using a polystyrene bead prior to each set of measurements.

All measurements were carried out by shielding the specimen and instrument contact area using a black cloth to avoid spectral interference from room light. The roughly $100 \mu \mathrm{m}$ sized laser spot was focused at few millimeters of distance from the Raman probe head window. The depth of focus is also in the millimeter range, allowing a simple positioning of samples by hand. Taking into account the large laser spot and the lack of rigid mounts for positioning, we had a real spatial resolution in the range of few cubic millimeter. This could be a disadvantage when analyzing very small features or heterogeneous materials. On the other hand, as we had a large volume of scattering, it was easy to focus the laser beam on the gems, and we obtained unexpected information on surrounding elements (pigments on the gem mounts, glass parts of the gem, etc.), even when they were not visible with the naked eye. Because of the relatively large spot size, the laser power per unit area was too weak to induce any undesired effect or damage, even on organic or photosensitive materials.

Raman spectra were exported into the Galactic .spc format. The spectra were compared using GRAMS AI (Version 8.0, Thermo Electron Corp., Waltham, MA, USA). The Raman spectra were not subjected to any data manipulation or processing techniques and are reported generally as collected.

\section{Results and discussion}

On each of the described jewels, different measurements were carried out on the more valuable gems and glasses whose autoptic identification was questionable. In Table 2, the analyzed objects with their autoptic classification, the main Raman bands (in $\mathrm{cm}^{-1}$ ) and their identification are reported. The results are reported following the autoptic classification of the gems.

\begin{tabular}{|c|c|c|c|c|}
\hline Sample ID & Gems analyzed & Autoptic classification & Main Raman features $\left(\mathrm{cm}^{-1}\right)$ & Attribution \\
\hline \multirow[t]{2}{*}{ A96a } & Gems $a, c, d, f$ & Topaz & 465 & Quartz \\
\hline & Gems $b$ and e & Topaz & Broadband centered at 1400 & Yellow glass \\
\hline A96b & Gem a (top and down) & Agate & 465 & Quartz \\
\hline A104 & Gem b & Diamond & $256,546,598,673,785,1227,1333$ & Diamond + indigo \\
\hline A105 & Gem a, b & Glass & Broadbands centered at 500 and 1400 & Red glass simulants \\
\hline \multirow[t]{3}{*}{ A106 } & Gems $a, b$ & Rubies & Broadbands & Glass simulants \\
\hline & Gem c & Rubies & $402,662,764$ & Spinel \\
\hline & Gem d & Rubies & $409,664,764$ & Spinel \\
\hline A107 & Gem $a, a_{2}, c$ & Emeralds & 685 & Emeralds \\
\hline \multirow[t]{3}{*}{ A108 } & Gem a & Ruby & $376,417,747$ & Ruby \\
\hline & Gem b & Ruby & Broadbands & Glass \\
\hline & Gem c & Ruby & 378,420 & Ruby \\
\hline \multirow[t]{2}{*}{ A113 } & Gems a, c & Diamonds & 1333 & Diamonds \\
\hline & Gem b & Pearl & 703,1085 & Aragonite-pearl \\
\hline A115 & Gem a & Diamond & 464,1331 & Doublet diamond + quartz \\
\hline \multirow[t]{2}{*}{ A119 } & Gems $a, b$ & Diamond & Broadband centered at 1400 & Glass simulants \\
\hline & Gems c, d & Ruby & $367,559,864,918$ & Garnets \\
\hline \multirow[t]{2}{*}{ A121 } & Gem b & Ruby & $409,666,764$ & Spinel \\
\hline & Gem c & Ruby & $379,420,645$ & Ruby \\
\hline A123 & Gem a & Diamond & 1331 & Diamond \\
\hline \multirow[t]{2}{*}{ A125 } & Gem a & Diamond & 1331 & Diamond \\
\hline & Gem b & Ruby & $378,417,645$ & Ruby \\
\hline \multirow[t]{2}{*}{ A128 } & Gem d & Emerald & 683 & Emerald \\
\hline & Gems $a, b$ & Rubies & $376,418,645$ & Rubies \\
\hline A160 & Gems a, b & Glass & Broadbands & Glass \\
\hline
\end{tabular}




\section{Topaz}

In the set of the examined jewels, the only gems recognized by autoptic analysis as topaz are those of sample A96a. Raman spectra indicate that all the analyzed gemstones are simulants, that is, natural or manmade materials used to substitute a gem thanks to their similar aspect (Figure 1). In particular, gems (a, c, d, and f) are formed by quartz (main Raman band $\sim 465 \mathrm{~cm}^{-1}$ ), whereas gems (b and e) show a broad band at $\sim 1400 \mathrm{~cm}^{-1}$, typical of glass.

\section{Agates}

Natural and less valuable gems classified as agate, a colored variety of chalcedony, have been used in the necklace A96b; Raman analysis confirms the attribution revealing the typical spectrum of quartz both on the top and the bottom part of the gems (Figure 2). In addition, small bands at nearly $500 \mathrm{~cm}^{-1}$ reveal the presence of minor amounts of moganite, the silica monoclinic polymorph present in chalcedony.

\section{Diamonds}

Many of the colorless gems were classified as diamonds. In the samples A113-gems (a and c) (Figure 3), A123-gem (a) (Fig. S1=supporting information) and A125-gem (a) (Fig. S2) the Raman analysis reveals the typical spectrum of diamond (main feature at $\sim 1332 \mathrm{~cm}^{-1}$ ). On the contrary, in the earrings A119 - gems ( $\mathrm{a}$ and b) (Fig. S3), the believed diamond is indeed a glass simulant as testified by the Raman broad band at $\sim 1400 \mathrm{~cm}^{-1}$. In the cross pendant A115-gem (a) (Figure 4), diamond and quartz are both present, suggesting a doublet gem instead of a pure diamond.

Finally, in a blue stone in pendant A104 (Figure 5), the Raman bands of diamond and of indigo blue dye are present in the same spectra. This suggests that the bottom of the diamond mount was blue painted, in order to give an unusual grey-blue hue to the white gemstones: this was a well-known practice to obtain a specific chromatic effect for transparent gems. The very long depth
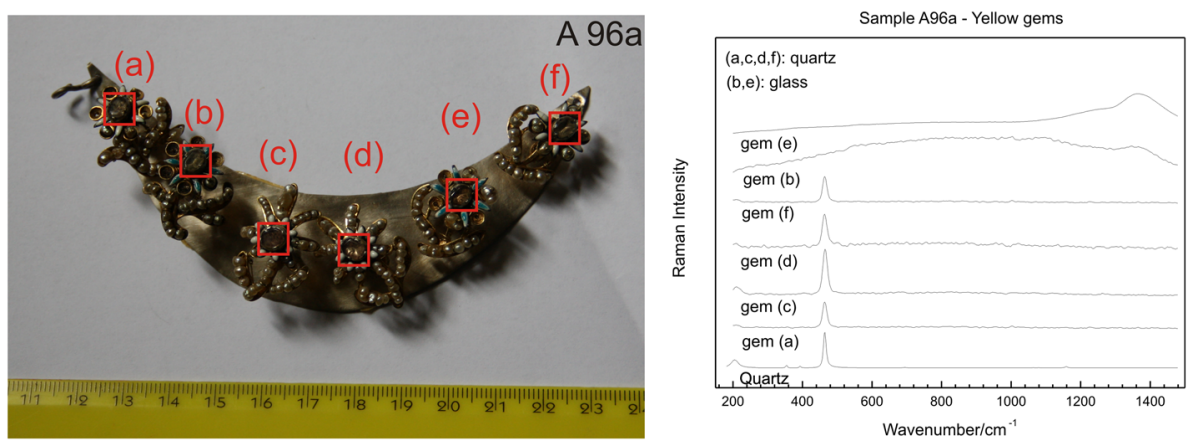

Figure 1. Messinian goldsmith's artifact of XVIII century (Messina Regional Museum, inv. A96a).
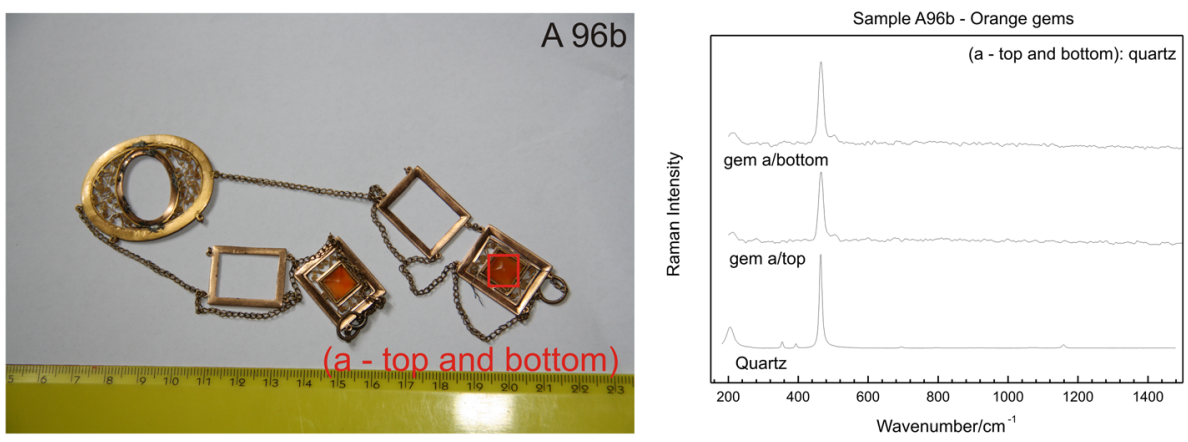

Figure 2. Messinian goldsmith's artifact of XVIII century (Messina Regional Museum, inv. A 96b).
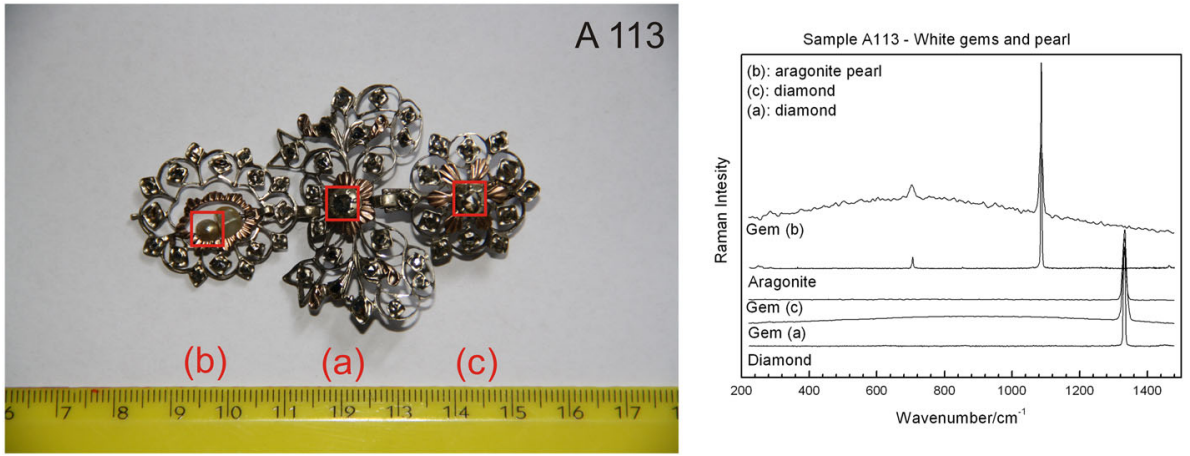

Figure 3. Messinian goldsmith's artifact of XVIII-XIX centuries (Messina Regional Museum, inv. A 113) 

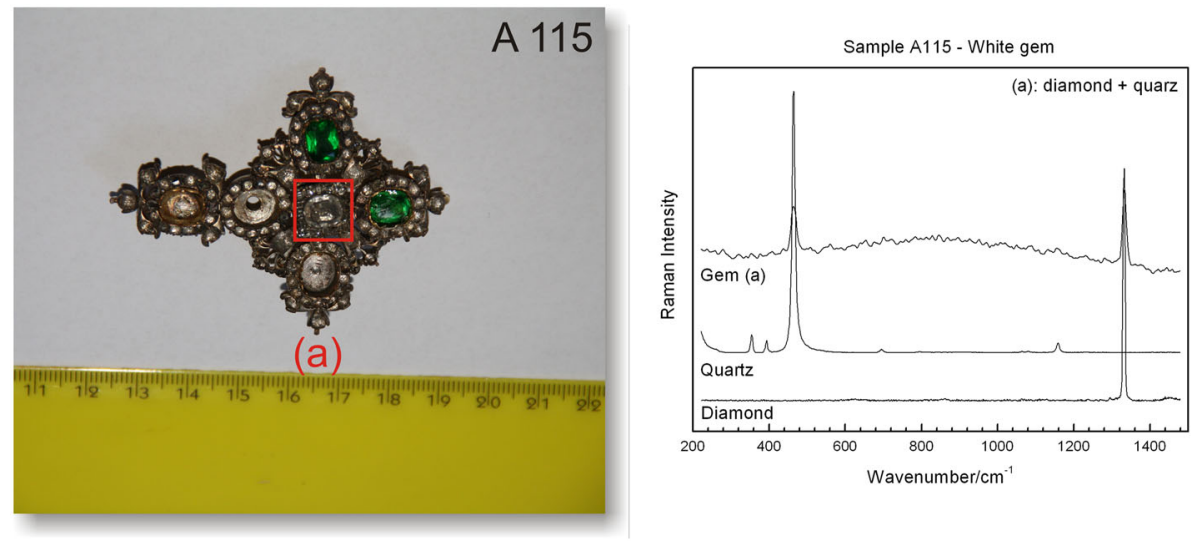

Figure 4. Messinian goldsmith's artifact of XVIII century (Messina Regional Museum, inv. A 115).
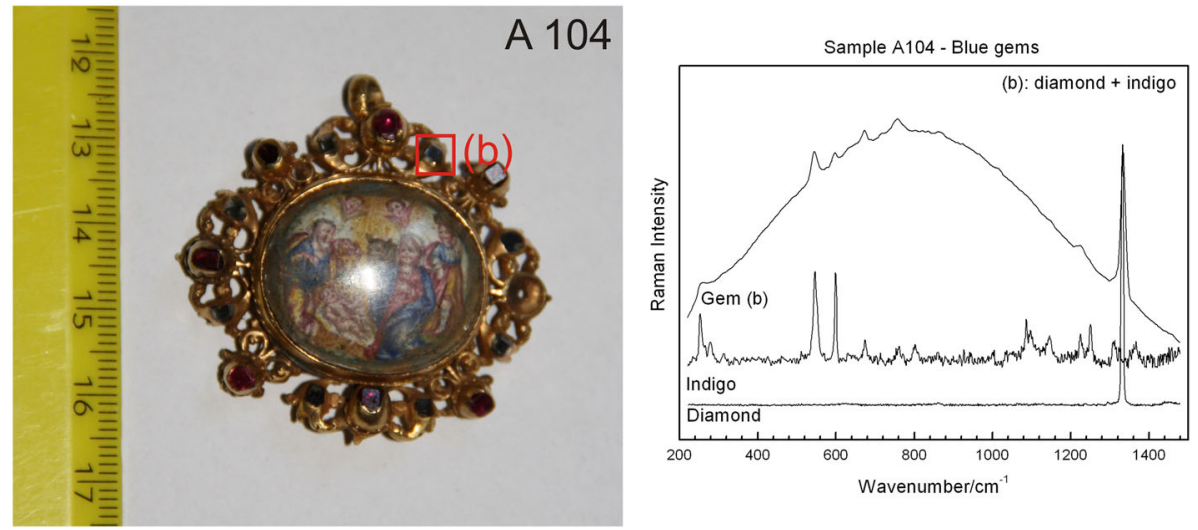

Figure 5. Messinian goldsmith's artifact of XVIII century (Messina Regional Museum, inv. A104).

of field typical of the handheld instruments allows the acquisition of a signal from the bottom of the mount.

\section{Rubies}

Among the analyzed red gems classified as rubies, only samples A108 gems (a and c) (Figure 6), A121 gem (c) (Figure 8), A125 gem (b) (Fig. S2) and A128 gems (a and b) (Fig. S4) are certainly rubies (main Raman features at $\sim 378, \sim 417, \sim 645 \mathrm{~cm}^{-1}$ ). The use of natural red gems as simulant for replacing rubies was a common practice. In detail, Raman analysis reveals the use of

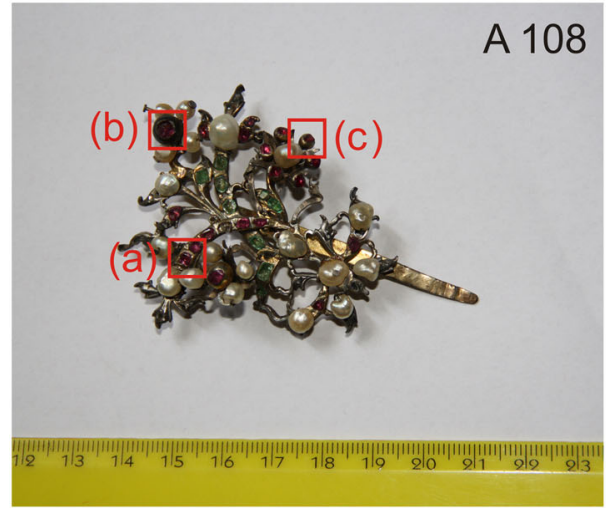

spinel (Raman main bands centered at $\sim 402, \sim 662, \sim 764 \mathrm{~cm}^{-1}$ ) in the brooch A106, gems ( $c$ and d) (Figure 7) and in the earring A121, gem (b) (Figure 8). We want to point out that the main bands of spinel and ruby are close. When using low-resolution spectrometers and in presence of the strong fluorescence of $\mathrm{Cr}^{3+}$ ions (especially using the 785-nm laser line as excitation) it is easy to confuse them.

Another mineral used as ruby simulant is garnet (main Raman features centered at $\sim 367, \sim 559, \sim 864, \sim 918 \mathrm{~cm}^{-1}$ ) found in the sample A119 gems (c and d) (Fig. S3). Here, the detected bands are typical of an almandine garnet. ${ }^{[18]}$ Finally, worthy of note is

Figure 6. Messinian goldsmith's artifact of XVIII century (Messina Regional Museum, inv. A108).

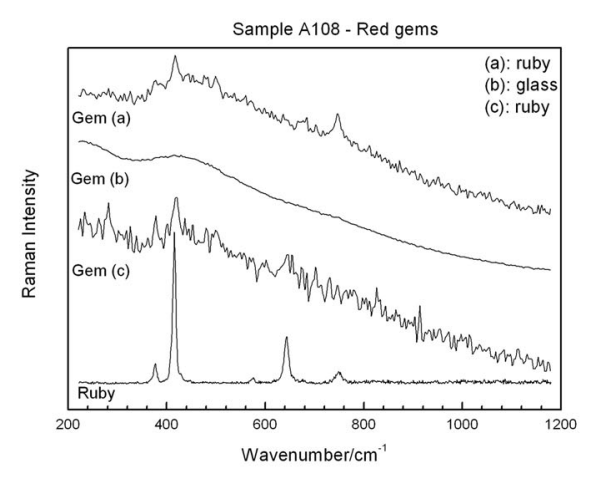



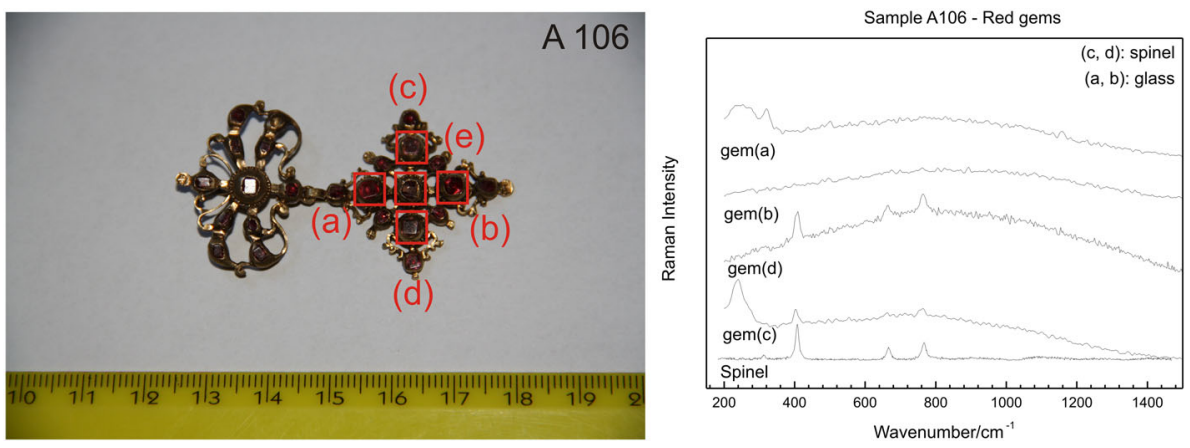

Figure 7. Messinian goldsmith's artifact of XVIII century (Messina Regional Museum, inv. A106).
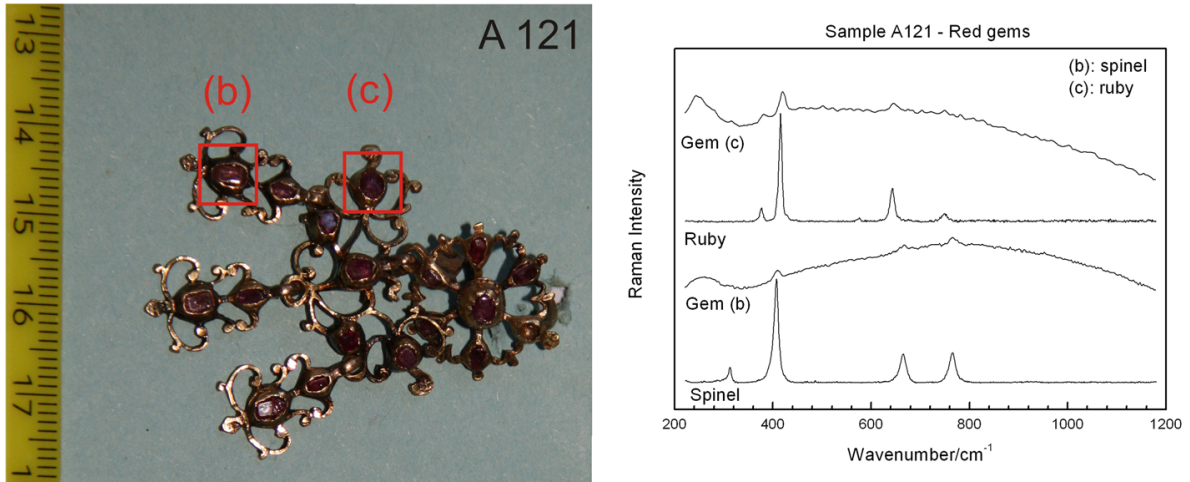

Figure 8. Messinian goldsmith's brooch (Messina Regional Museum inv. A121).
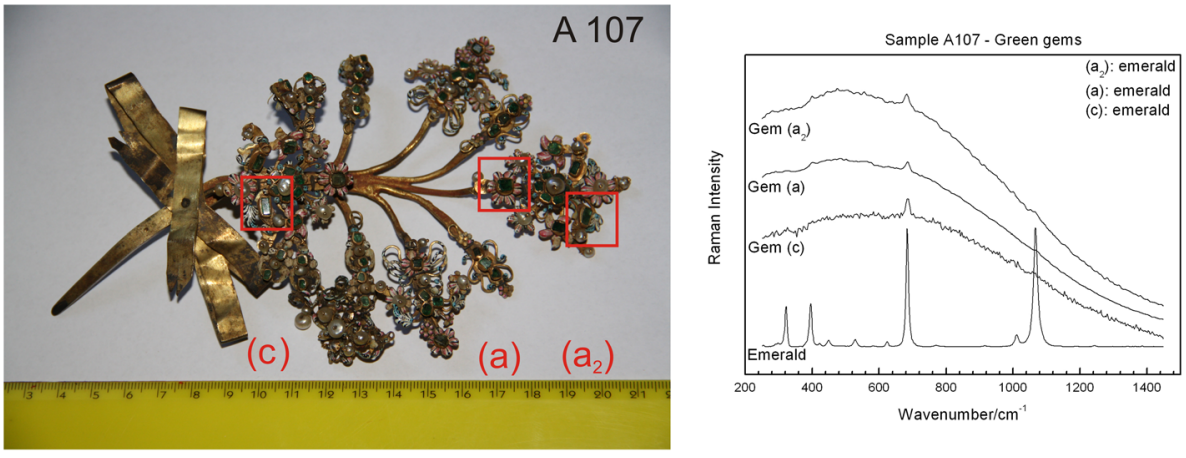

Figure 9. Messinian goldsmith's artifact of XVII century (Messina Regional Museum, inv. A 107).
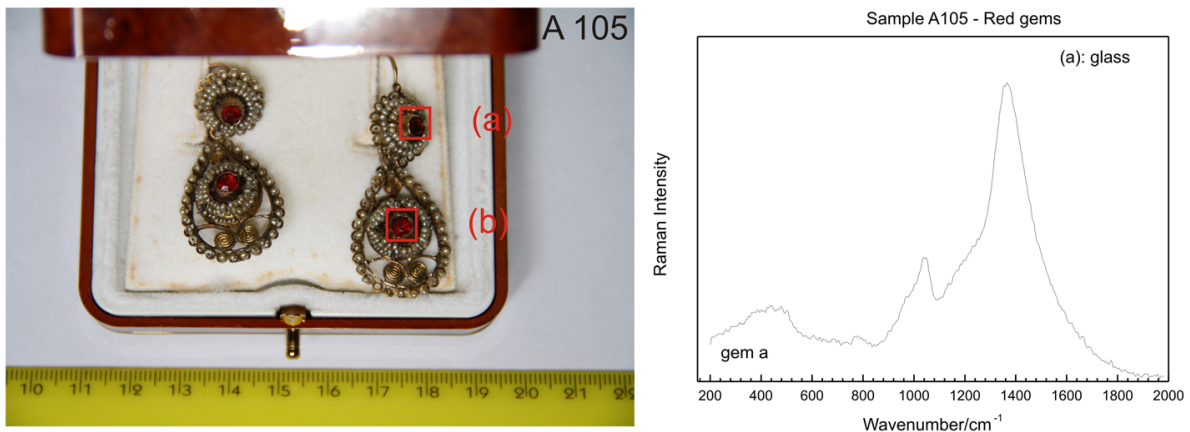

Figure 10. Messinian goldsmith's earring of 1839-1873 (Messina Regional Museum, inv. A 105). 
the use of glass instead of rubies, demonstrated by the presence of broad bands in the Raman spectra: samples A106 gems (a and b) (Figure 7) and A108 gem (b) (Figure 6).

\section{Emeralds}

In Figure 9 and S4, the Raman spectra of A107 gems (a, $a_{2}$, and c), and $A 128$ gem (d) collected on green gems are reported. Even if the strong fluorescence of $\mathrm{Cr}^{3+}$ ions expected in emeralds when exciting with the 785-nm line, hinders most of the Raman peaks the typical main mode of emeralds (centered at $\sim 685 \mathrm{~cm}^{-1}$ ) is clearly visible.

\section{Pearls}

The bands of aragonite, at $703 \mathrm{~cm}-1$ and $1085 \mathrm{~cm}-1$, in the Raman spectra of sample A113 gem (b) (Figure 3) confirm that this is a pearl. No signal due to natural or synthetic dyes is detected.

\section{Glass simulant}

The use of natural or glass simulant is very common in manufacturing less valuable jewels: examples of this procedure are represented by the earring A105 gems ( $a$ and b) (Figure 10) and the belt A160 gems ( $\mathrm{a}$ and b) (Fig.S5). In these cases, the autoptic classification resulted correct as evidenced by the Raman broad bands centered at $\sim 500$ and $\sim 1400 \mathrm{~cm}^{-1}$.

\section{Conclusions}

The results of the analyses performed at the Interdisciplinary Regional Museum Maria Accascina on different jewels emphasize the potentiality of portable Raman instruments for the identification of gems. Worthy of note is that the measurements are completely nondestructive and very fast. The use of the 785-nm line as excitation generated a lot of fluorescence, because most of the important gems (beryls, corundums) contain $\mathrm{Cr}^{3+}$ ions. Nevertheless, it was possible for all the analyzed gems to obtain Raman spectra useful for their identification. The spectral resolution, even if lower than for a laboratory equipment, was good enough to distinguish the almandine variety between the garnets. The spectra obtained on numerous gems autoptically classified as topaz, agate, diamond, ruby, emerald, pearl, and glass in many cases supported the hypotheses of the museum curators. However, Raman measurements also revealed misclassification, especially for the most valuable gems such as topaz, diamonds, and rubies. Raman analysis detected different simulants, in particular quartz, colorless or red glass, doublets, spinels, and almandine garnets. The presence of unprecious gemstones in important artifacts is well known in old jewels because of conscious or unconscious choices of the jeweler. Alternatively, it may be brought by historical events, which determine the substitution of some parts of them.

In this context, the new data acquired on jewels allow to obtain useful and unknown information on manufacturing and history of the studied art objects, opening new interesting questions about the Sicilian goldsmith art during XVII-XVIII centuries.

\section{References}

[1] D. Bersani, P. P. Lottici, Anal. Bioanal. Chem. 2010, 397, 2631.

[2] L. Kiefert, S. Karampelas, Spectrochim. Acta A 2011, 80, 119.

[3] M. L. Dele-Dubois, P. Dhamelincourt, J. P. Poirot, H. J. Schubnel, J. Mol. Struct. 1986, 143, 135

[4] J. Jehlička, P. Vítek, H. G. M. Edwards, M. Heagraves, T. Čapoun, Spectrochim. Acta A 2009, 73, 410.

[5] J. Jehlička, A. Culka, P. Vandenabeele, H. G. M. Edwards, Spectrochim. Acta A 2011, 80, 36.

[6] J. Jehlička, P. Vandenabeele, H. G. M. Edwards, Spectrochim. Acta A 2012, 86, 341

[7] P. Vitek, J. Jehlička, H. G. M. Edwards, Appl. Spectrosc. 2013, 67, 767.

[8] H. A. Hänni, B. Schubiger, L. Kiefert, S. Häberli, Gems Gemol. 1998, 34, 102.

[9] R. J. H. Clark, J. Van der Weerd, J. Raman Spectrosc. 2004, 35, 279.

[10] I. Reiche, S. Pages-Camagna, L. Lambacher, J. Raman Spectrosc. 2004, $35,719$.

[11] S. Karampelas, M. Worle, K. Hunger, H. Lanz, D. Bersani, S. Gubelin, Gems Gemol. 2010, 46, 292.

[12] Z. Petrová, J. Jehlička, T. Čapoun, R. Hanus, T. Trojek, V. Goliáš, J. Raman Spectrosc. 2012, 43, 1275.

[13] K. Osterrothová, L. Minaříková, A. Culka, J. Kuntoš, J. Jehlička J. Raman Spectrosc. 2014, 45, 830.

[14] G. Barone, D. Bersani, V. Crupi, F. Longo, U. Longobardo, P. P. Lottici, I. Aliatis, D. Majolino, P. Mazzoleni, S. Raneri, V. Venuti, J. Raman Spectrosc. 2014,45, pp. 1309-1317.

[15] D. Bersani, G. Azzi, E. Lambruschi, G. Barone, P. Mazzoleni, S. Raneri, U. Longobardo, P.P. Lottici, J. Raman Spectrosc. 2014, 45, pp. 1293-1300.

[16] G. Larinà, in Archivio Storico Messinese, 91/92, Società Messinese di Storia Patria, Messina, 2010-2011, pp. 465-475.

[17] G. Larinà, in Sizilien - Von Odysseus bis Garibaldi, Catalogue, (Eds: G. Macchi, W. D. Heilmeyeri), Kunst-und Ausstellungshalle der Bundesrepublik Deutschland, Bonn, 2008, pp. 246-250.

[18] D. Bersani, S. Andò, P. Vignola, G. Moltifiori, I.-G. Marino, P. P. Lottici, V. Diella, Spectrochim. Acta A 2009, 73, 484.

\section{Supporting information}

Additional supporting information may be found in the online version of this article at the publisher's web site. 